\title{
Islands of Mytilus edulis as a habitat for small intertidal animals: effect of Mytilus age structure on the species composition of the associated fauna and community organization*
}

\author{
M. Tsuchiya ${ }^{1, * *} \&$ M. Nishihira ${ }^{2, * *}$ \\ ${ }^{1}$ Marine Biological Station, Tohoku University, Asamushi, Aomori 039-34, Japan \\ ${ }^{2}$ Laboratory of Animal Ecology, Department of Zoology, Kyoto University, Kyoto 606, Japan
}

\begin{abstract}
Community structure of the associated animals of low intertidal patches of Mytilus edulis L. with different age structure was investigated at Asamushi, northern Japan. Each patch was composed of similar components i.e. live $M$. edulis, byssal threads, shell fragments, sediments, algae and associated animals. The amounts of sediments, shell fragments and byssal threads were greater in the periphery (MP) and central part (MC) of adult mussel patches than in patches of young (Y) and old (O) mussels. Total organic matter within sediments increased in the following order: O, MC, MP and Y. Algal growth was luxuriant in $Y$ and this supported abundant amphipods. Species richness was higher in older patches and species diversity $\left(\mathrm{H}^{\prime}\right)$ and equitability $\left(\mathrm{J}^{\prime}\right)$ were higher in MP and MC than in $\mathrm{Y}$ and $O$. Sediments, shell fragments and byssal threads seemed to play an important role in increasing heterogeneity of environments and thus species diversity. Similarities in species compositions among $\mathrm{MP}, \mathrm{MC}$ and $\mathrm{O}$ were high, but those between $\mathrm{Y}$ and other patches extremely low. This fact is probably caused both by the presence of a large number of epiphytic animals in $Y$ and the difference in the composition of creeping fauna among the patches. Based on these results, the processes controlling community organization of Mytilus islands are discussed.
\end{abstract}

\section{INTRODUCTION}

It is well known that in the rocky intertidal zone, patches of Mytilus spp. harbour a variety of small animals (Hewatt 1935, Suchanek 1979, 1985, Tsuchiya 1979, Tsuchiya \& Nishihira 1985). A community composed of $M$. edulis plus associated organisms is designated here as a Mytilus community. The dynamic process of Mytilus community organization and the effect of Mytilus age composition on the associated fauna have not been well studied. In Japan, Mytilus edulis frequently forms aggregations in discrete patches of various sizes (hereafter such patches are designated as Mytilus islands). Mytilus islands have common compo-

\footnotetext{
- Contribution from Marine Biological Station, Tohoku University No. 525; contribution from Laboratory of Animal Ecology, Kyoto University, No. 480

- Present address: Department of Biology, University of the Ryukyus, Nishihara, Okinawa 903-01, Japan
}

nents in addition to live $M$. edulis, i.e. byssal threads, shell fragments, sediments, algae and associated animals (Tsuchiya \& Nishihira 1985). Moreover, amounts of these components vary among patches according to differences in age (or size) composition. It is likely that the Mytilus island as a habitat for associated organisms is steadily changing, because it is composed of living mussels. Dynamic aspects of this community, therefore, should be studied in relation to the change in $M$. edulis population (growth and death).

For Mytilus islands composed of young mussels of similar age class ( $<20 \mathrm{~mm}$ in shell length), Tsuchiya \& Nishihira (1985) discussed the effect of island size on the community structure of the associated animals. In the present paper, we describe the effects of the physical structure of Mytilus islands with different age composition on the community structure and discuss the process of community development within Mytilus islands. 


\section{MATERIALS AND METHODS}

Patches of Mytilus edulis L. with different age compositions were studied on a concrete slope in the lower intertidal ( 5 to $20 \mathrm{~cm}$ above MLWS, inclination of $10^{\circ}$ ) in a small harbour of the Marine Biological Station, Tohoku University $\left(40^{\circ} 55^{\prime} \mathrm{N}, 140^{\circ} 50^{\prime} \mathrm{E}\right)$. Among such Mytilus islands, 3 patches were sampled during daytime low tides in June 1980. The first patch of mussels $(<30 \mathrm{~mm}$ in shell length) was irregularly shaped measuring about 15 to $30 \mathrm{~cm}$ width by $70 \mathrm{~cm}$ length. The second patch was an ellipsoid $11.0 \mathrm{~m} \times$ $5.0 \mathrm{~m}$ ) consisting of mussels 25 to $45 \mathrm{~mm}$ in length, and the third was of larger mussels ( 35 to $55 \mathrm{~mm}$ long) with eroded shells and of $20 \mathrm{~cm} \times 30 \mathrm{~cm}$ in patch size. Five samples (each $10 \mathrm{~cm} \times 10 \mathrm{~cm}$ ) were collected from the central part of each patch and from the periphery of the second patch after taking photographs and measurements of patch thickness (height above substratum). Hereafter we refer to samples from the first patch as ' $\mathrm{Y}$ ' (young), those of the second ' $\mathrm{M}$ ' (medium) and those from the third ' $O$ ' (old). The central and peripheral samples of the second patches are designated by adding the letters ' $\mathrm{C}$ ' (central) and ' $\mathrm{P}$ ' (peripheral), respectively. Age was determined using shell characteristics such as size, color and degree of erosion.

Total displacement volume was measured first for each total sample wrapped in a thin polyethylene sheet and then for each constituent; i.e. live Mytilus edulis, byssal threads, shell fragments, sediments, algae attached to mussels and associated macrobenthic animals. Space in the Mytilus patch was estimated by subtracting the volume of all constituents of the patch from the total displacement volume. Associated animals were identified and counted. Species diversity ( $\mathrm{H}^{\prime}$ using $\log _{2}$ ) and Pielou's equitability $\left(\mathrm{J}^{\prime}\right)$ in each patch, and similarity of species composition between patches (Kimoto's $\mathrm{C}_{\Pi}$ ) were calculated. The formula for $\mathrm{C}_{\Pi}$ (Kimoto 1967) is as follows;

$$
\begin{gathered}
C_{\Pi \tau}=\frac{2 \sum_{i=1}^{s} n_{1 i} \cdot n_{2 i}}{\left(\sum \Pi_{1}^{2}+\sum \Pi_{2}^{2}\right) N_{1} \cdot N_{2}} 0 \leqq C_{\Pi} \leqq 1 \\
\sum \Pi_{1}^{2}=\frac{\sum_{i=1}^{s} n_{1 i}^{2}}{N_{1}^{2}}, \sum \Pi_{2}^{2}=\frac{\sum_{i=1}^{s} n_{2 i}^{2}}{N_{2}^{2}}
\end{gathered}
$$

where $N_{1}$ and $N_{2}=$ total number of individuals occurring in the 1st and 2 nd areas; $n_{1}$ and $n_{2 i}=$ number of individuals of ith species in each area; $s=$ total number of species occurring in both areas. If overlap is complete, the index is 1 , and if there is no overlap, it is 0 . Total organic content of the sediments was estimated from weight loss on ignition $\left(500^{\circ} \mathrm{C}, 2 \mathrm{~h}\right)$.

\section{RESULTS}

\section{Nature of the patches}

Table 1 shows patch size and volume of each component. MC had the largest volume of each component except algae and associated animals. The algae were mostly Chondria crassicaulis and Laurencia okamurai and were abundant in $\mathrm{Y}$. Associated animals were most abundant in $O$. Sediments accumulated more in $\mathrm{MP}$ and $\mathrm{MC}$ than in $\mathrm{Y}$ and $\mathrm{O}$, and their total organic content was largest in MP and least in Y. Shell fragments were extremely scarce in Y. Volume of space (total displacement volume minus volume of all components) varied widely among patches. The relative amount of space (space volume/total displacement volume) was fairly constant ( 38.1 to $44.5 \%$ ).

\section{Size distribution of Mytilus edulis}

Young Mytilus patches ( $\mathrm{Y}$ ) contained nearly an order of magnitude more very small $(<5 \mathrm{~mm})$ mussels than the medium aged (MC and MP) or old (O) patches

Table 1. Patch size and volume of components of the Mytilus patch $(10 \mathrm{~cm} \times 10 \mathrm{~cm})$. Y: young; MP: medium age/periphery; MC: medium age/center; $\mathrm{O}$ : old

\begin{tabular}{|crrrrrr}
\hline & $Y$ & MP & MC & \multicolumn{1}{c}{ O } \\
\hline Thickness $(\mathrm{mm})$ & $27.1 \pm 5.1$ & $42.8 \pm 6.0$ & $56.2 \pm 7.7$ & $42.2 \pm 1.2$ \\
Total volume $\left(\mathrm{cm}^{3}\right)$ & $233.1 \pm 70.2$ & $407.4 \pm 70.8$ & $532.2 \pm 62.8$ & $354.3 \pm 82.5$ \\
Components $\left(\mathrm{cm}^{3}\right)$ & & & & \\
Mytilus edulis & $133.9 \pm 39.6$ & $185.5 \pm 27.4$ & $259.9 \pm 61.7$ & $168.2 \pm 26.0$ \\
Byssal threads & $1.6 \pm 0.6$ & $3.5 \pm 0.8$ & $4.2 \pm 0.7$ & $2.4 \pm 0.6$ \\
Shell fragments & $1.3 \pm 0.7$ & $12.6 \pm 4.1$ & $19.7 \pm 6.3$ & $11.7 \pm 5.0$ \\
Sediments & $2.1 \pm 0.6$ & $20.9 \pm 15.2$ & $23.6 \pm 13.2$ & $4.2 \pm 1.9$ \\
(Loss on ignition, \%) & $10.8 \pm 0.2)$ & $(2.8 \pm 0.4)$ & $(3.2 \pm 0.5)$ & $(3.6 \pm 1.6)$ \\
Space & $88.9 \pm 24.2$ & $181.3 \pm 46.1$ & $220.4 \pm 20.8$ & $159.1 \pm 51.1$ \\
Algae & $3.8 \pm 1.7$ & $0.9 \pm 0.7$ & $0.5 \pm 0.3$ & $0.4 \pm 0.5$ \\
Associated animals & $1.5 \pm 0.7$ & $2.7 \pm 1.8$ & $3.9 \pm 1.0$ & $8.3 \pm 2.6$ \\
\hline
\end{tabular}


(Fig. 1). In $Y$, young mussels of 10 to $30 \mathrm{~mm}$ shell length were also found together with many recently settled smaller ones. Size distributions in MP and MC were comparable having many larger mussels (25 to $45 \mathrm{~mm}$ long). The $O$ samples were composed of a monolayer of large mussels (35 to $55 \mathrm{~mm}$ ) and few small ones. The peaks in the size-frequencies are to be taken as year classes. The mussels attached to one another in $\mathrm{MC}$, and those in $\mathrm{Y}$ and MP were multilayered.

\section{Associated animals in each patch}

A species-area curve based on 5 samples of increasing area was drawn for each island (Fig. 2). Although none of the curves reached a plateau, it is considered that our samples (in total $500 \mathrm{~cm}^{2}$ for each island) include about $80 \%$ of species expected to be found in the island. Tsuchiya (1979) listed macrobenthic fauna of the rocky intertidal at Asamushi area. About 80 species were expected to be seen in a Mytilus bed. We collected 69 species in the present study, and they

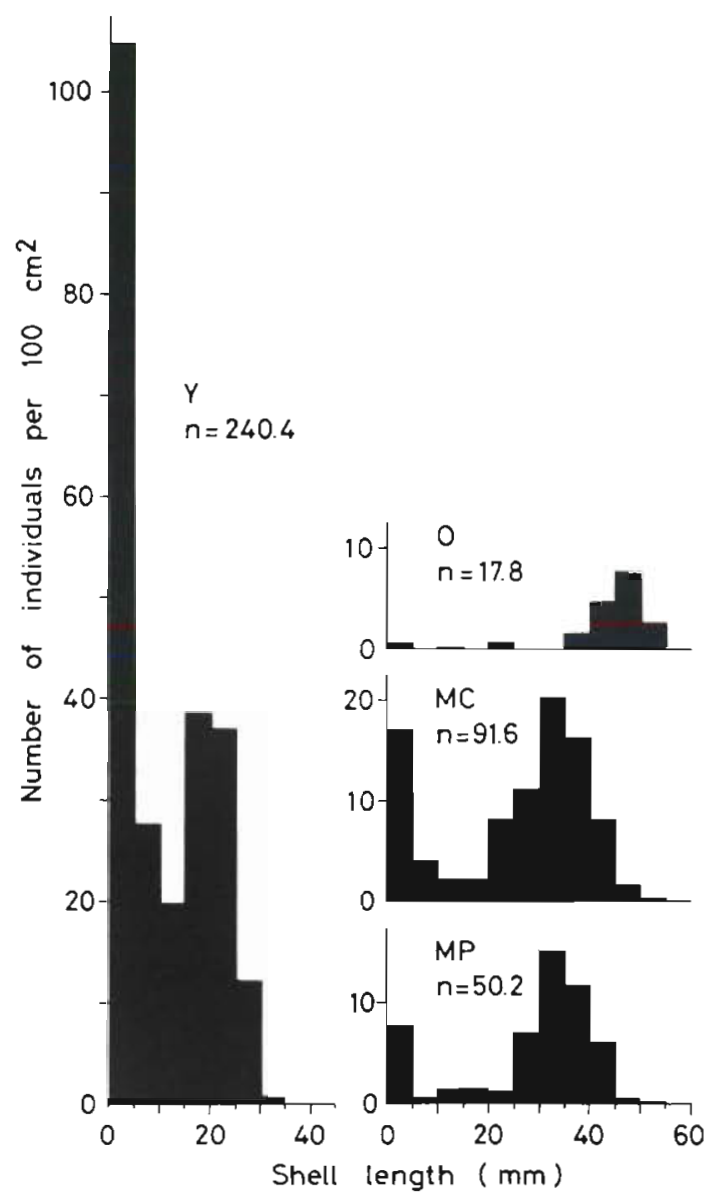

Fig. 1. Mytilus edulis. Size composition for each patch. $\mathrm{n}$ : total number of $\mathrm{M}$. edulis per $100 \mathrm{~cm}^{2}$ were mostly included in the faunal list. These facts suggest that our samples describe well the species richness of each Mytilus island.

Table 2 shows the species-number relation of the associated animals for each patch. Number of species increased with age, but the number of individuals of associated animals were more abundant in MP and $\mathrm{MC}$ than in $\mathrm{Y}$ and $\mathrm{O}$. The number of individuals per area was nearly equal in both $Y$ and $O$, but on a per volume basis was larger in $Y$. The number of species per volume was largest in $Y$. Species diversity $\left(\mathrm{H}^{\prime}\right)$ and equitability $\left(\mathrm{J}^{\prime}\right)$ were larger in $\mathrm{MP}$ and $\mathrm{MC}$ than in $\mathrm{Y}$ and $\mathrm{O}$.

Table 3 shows the members of associated fauna established in the patches of different age class. Although animals belonging to 8 phyla appeared, $93.9 \%$ of total specimens were shared by 2 phyla: Annelida and Arthropoda. The most abundant species was the orbinid polychaete worm Nainereis laevigata, which was extremely abundant in $O$, but not seen in $Y$. The arabellid polychaete Arabella iricolor was also abundant in $\mathrm{O}$ and rather large specimens $(>200 \mathrm{~mm}$ long) were collected. This explains the largest volume of associated animals in $O$ (Table 1). In other patches, only small worms were seen. On the other hand, the amphipod Hyale grandicornis was extremely concentrated in $Y$. A similar trend was observed in the amphipod Mellita sp. and the nereid worm Nereis pelagica. Several species which were restricted to $O$

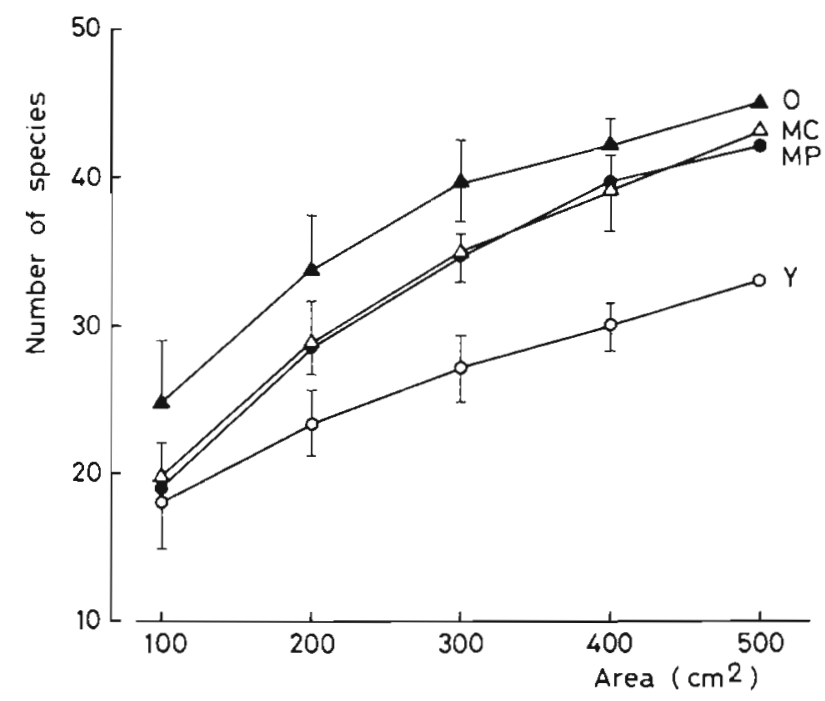

Fig. 2. Species-area relation in Mytilus islands composed of mussels of different ages. Y: Mytilus island with young mussels; MP: peripheral part of the island of adult mussels; MC: central part of the island of adult mussels; $O$ : island consisting of old mussels. Bars indicate SD; we collected 5 samples in each patch and mean values of possible combinations for each area were calculated, so we have only 1 sample for $500 \mathrm{~cm}^{2}$ 
Table 2. Relation between numbers of species and individuals (species diversity and equitability) in each patch $\left(500 \mathrm{~cm}^{2}\right)$. Means ( $\pm \mathrm{SD})\left(100 \mathrm{~cm}^{2}\right)$ are also shown in parentheses. Y young; MP: medium age/peripheral; $\mathrm{MC}$ : medium age/center; $\mathrm{O}:$ old

\begin{tabular}{|c|c|c|c|c|}
\hline & $\mathrm{Y}$ & MP & $\mathrm{MC}$ & $\mathrm{O}$ \\
\hline Number of species & $\begin{array}{c}33 \\
(18.0 \pm 3.16)\end{array}$ & $\begin{array}{c}42 \\
(19.0 \pm 0)\end{array}$ & $\begin{array}{c}43 \\
(19.8 \pm 2.22)\end{array}$ & $\begin{array}{c}45 \\
(24.8 \pm 4.26)\end{array}$ \\
\hline Number of individuals & $\begin{array}{c}595 \\
(119.0 \pm 28.65)\end{array}$ & $\begin{array}{c}251 \\
(50.2 \pm 12.56)\end{array}$ & $\begin{array}{c}292 \\
(58.4 \pm 6.86)\end{array}$ & $\begin{array}{c}554 \\
(110.8 \pm 21.74)\end{array}$ \\
\hline Number of species $\mathrm{cm}^{-3}$ & $\begin{array}{c}0.074 \\
(0.20 \pm 0.07)\end{array}$ & $\begin{array}{c}0.046 \\
(0.09 \pm 0.03)\end{array}$ & $\begin{array}{c}0.039 \\
(0.08 \pm 0.01)\end{array}$ & $\begin{array}{c}0.057 \\
(0.20 \pm 0.09)\end{array}$ \\
\hline Number of individuals $\mathrm{cm}^{-3}$. & $\begin{array}{c}1.339 \\
(1.25 \pm 0.38)\end{array}$ & $\begin{array}{c}0.277 \\
(0.24 \pm 0.06)\end{array}$ & $\begin{array}{c}0.265 \\
(0.22 \pm 0.04)\end{array}$ & $\begin{array}{c}0.696 \\
(0.69 \pm 0.34)\end{array}$ \\
\hline $\begin{array}{l}\mathrm{H}^{\prime} \\
\mathrm{H}_{\max }^{\prime} \\
\mathrm{J}^{\prime}\end{array}$ & $\begin{array}{l}3.154 \\
5.044 \\
0.625\end{array}$ & $\begin{array}{l}4.274 \\
5.392 \\
0.793\end{array}$ & $\begin{array}{l}4.245 \\
5.426 \\
0.782\end{array}$ & $\begin{array}{l}3.537 \\
5.524 \\
0.640\end{array}$ \\
\hline
\end{tabular}

Table 3. Faunal list collected in each patch. Total number of individuals in 5 quadrats $\left(100 \mathrm{~cm}^{2}\right.$ each) are shown for each species

\begin{tabular}{|c|c|c|c|c|c|c|c|c|c|}
\hline Species & $\mathrm{Y}$ & MP & $\mathrm{MC}$ & $\mathrm{O}$ & Species & $\mathrm{Y}$ & MP & $\mathrm{MC}$ & $\mathrm{O}$ \\
\hline COELENTERATA & (0) & (1) & (2) & $(0)$ & MOLLUSCA & (35) & $(40)$ & $(52)$ & (91) \\
\hline Anthopleura japonica & 0 & 0 & 2 & 0 & Ischonochiton (s.s.) computus f. computus & 0 & 3 & 3 & 8 \\
\hline Unidentified actiniarian sp. 1 & 0 & 1 & 0 & 0 & Tonicella liniata & 0 & 1 & 0 & 0 \\
\hline PLATYHELMINTHES & (0) & (2) & (1) & $(0)$ & Acanthochiton rubrolineatus & 3 & 9 & 8 & 10 \\
\hline Notoplana humilis & 0 & 2 & 1 & 0 & Collisella (Conoidacmea) heroldi & 19 & 19 & 21 & 44 \\
\hline NEMERTINEA & (1) & $(7)$ & (7) & $(7)$ & Notoacmea schrenckii & 0 & 0 & 3 & 0 \\
\hline Emplectonema gracile & 0 & 1 & 3 & 0 & Littorina brevicula & 0 & 3 & 1 & 0 \\
\hline Amphiporus cervicalis & 0 & 2 & 1 & 3 & Temanella turita & 7 & 1 & 0 & 2 \\
\hline Unidentified nemertinean $s p .1$ & 1 & 0 & 0 & 4 & Mitrella tenuis & 4 & 1 & 8 & 4 \\
\hline Unidentified nemertinean sp. 2 & 0 & 0 & 2 & 0 & Septifer (Mytilisepta) virgatus & 0 & 4 & 7 & 0 \\
\hline Unidentified nemertinean sp. 3 & 0 & 4 & 1 & 0 & Septifer (Mytilisepta) keenae & 0 & 0 & 0 & 19 \\
\hline SIPUNCULOIDEA & (0) & (1) & (0) & (3) & Modiolus modiolus difficilis & 0 & 0 & 0 & 4 \\
\hline Unidentified sipunculid sp. 1 & 0 & 1 & 0 & 3 & Hiatella flaccida & 2 & 0 & 1 & 0 \\
\hline ANNELIDA & (131) & 139) & $(149)$ & $(357)$ & ARTHROPODA & $(428)$ & (59) & $(77)$ & (93) \\
\hline Harmothoe imbricata & 4 & 10 & 25 & 2 & Unidentified pycnogonid sp. 1 & 0 & 1 & 0 & 1 \\
\hline Lepidonotus sp. 1 & 3 & 4 & 1 & 9 & Chthamalus challengeri & 0 & 0 & 0 & 30 \\
\hline Lepidonotus sp. 2 & 1 & 0 & 0 & 1 & Paranthura japonica & 5 & 0 & 1 & 1 \\
\hline Halosydna brevisetosa & 0 & 1 & 0 & 0 & Exosphaeroma ovata & 0 & 1 & 0 & 1 \\
\hline Chrysopetalum occidentale & 0 & 2 & 1 & 4 & Dynoides dentisinus & 8 & 6 & 0 & 1 \\
\hline Unidentified syllid sp. 1 & 1 & 0 & 0 & 0 & Allorchestes plumicornis & 28 & 4 & 1 & 5 \\
\hline Unidentified syllid sp. 2 & 8 & 2 & 1 & 1 & Hyale grandicornis & 218 & 21 & 1 & 4 \\
\hline Unidentified syllid sp. 3 & 1 & 3 & 0 & 9 & Amphithoe lacertosa & 22 & 1 & 34 & 5 \\
\hline Genetyllis castanea & 2 & 2 & 6 & 3 & Melita sp. & 127 & 18 & 15 & 29 \\
\hline Euralia viridis & 1 & 1 & 0 & 1 & Elasmopus japonicus & 3 & 0 & 0 & 0 \\
\hline Eteone longa & 0 & 0 & 1 & 0 & Jassa falcata & 6 & 0 & 1 & 2 \\
\hline Nereis pelagica & 35 & 0 & 3 & 0 & Unidentified amphipod sp. & 1 & 0 & 1 & 1 \\
\hline Nereis heterocirrata & 4 & 6 & 0 & 0 & Caprella acutifrons & 6 & 0 & 0 & 0 \\
\hline Nereis sp. & 60 & 14 & 12 & 3 & Orchonemella sp. & 2 & 0 & 0 & 1 \\
\hline Lumbrineris latreilli & 0 & 2 & 1 & 4 & Pagurus germinus & 1 & 5 & 15 & 7 \\
\hline Arabella irricolor & 1 & 12 & 8 & 29 & Oedignathus inermis & 0 & 0 & 7 & 5 \\
\hline Arabella sp. & 7 & 0 & 0 & 1 & Hemigrapsus sanguineus & 1 & 2 & 1 & 0 \\
\hline Dorvillea matsushimaensis & 0 & 0 & 0 & 8 & ECHINODERMATA & $(0)$ & (1) & (4) & (2) \\
\hline Spio sp. & 0 & 1 & 7 & 0 & Ophiophragmus japonicus & 0 & 0 & 0 & 2 \\
\hline Cirriformia tentaculata & 0 & 6 & 9 & 4 & Unidentified ophiuroid sp. 1 & 0 & 1 & 1 & 0 \\
\hline Cirratulus cirratus & 0 & 0 & 0 & 1 & Aphelasterias japonica & 0 & 0 & 1 & 0 \\
\hline Nainereis laevigata & 0 & 64 & 66 & 249 & Cucumaria chronhjemi & 0 & 0 & 2 & 0 \\
\hline Stylarioides plumosa & 0 & 1 & 2 & 0 & Number of species & 33 & 42 & 43 & 45 \\
\hline Nicolea gracilibranchis & 0 & 1 & 3 & 6 & Number of individuals & 586 & 252 & 283 & 556 \\
\hline Unidentified sabellid sp. 1 & 3 & 7 & 3 & 12 & & & & & \\
\hline Hydroides ezoensis & 0 & 0 & 0 & 5 & & & & & \\
\hline Hydroides elegans & 0 & 0 & 0 & 5 & & & & & \\
\hline
\end{tabular}


were divided into 3 groups owing to their mode of life; (1) epizoic sessile animals such as the barnacle Chthamalus challengeri and the serpulids Hydroides ezoensis and $H$. elegans; (2) the mussels Septifer (Mytilisepta) keenae and Modiolus modiolus difficilis; (3) creeping fauna, the dorvilleid Dorvillea matsushimaensis and the ophiuroid Ophiophragmus japonicus.

Table 4 shows similarities of species composition $\left(\mathrm{C}_{\Pi}\right)$ between patches. Table 4 a shows values for whole animals. Patches MP, MC and $\mathrm{O}$ were highly similar in community structure. Table $4 \mathrm{~b}$ shows indices for animals excluding epiphytic species (e.g. amphipods and the gastropod Temanella turita living on algal thalli). Similarity between $\mathrm{Y}$ and other patches decreased when compared with the entire fauna, but increased among $M P, M C$ and $O$.

Table 4. Similarity of species composition between patches. $\mathrm{C}_{\Pi}$ indices are calculated (a) on total animals and (b) on animals excluding epiphytal species. $\mathrm{Y}$; young; MP: medium age/peripheral; $M C$ : medium age/center; $O$ : old

\begin{tabular}{|c|c|c|c|c|c|}
\hline & & $\mathrm{Y}$ & MP & $\mathrm{MC}$ & $\mathrm{O}$ \\
\hline (a) & $\begin{array}{l}\mathrm{Y} \\
\mathrm{MP} \\
\mathrm{MC} \\
\mathrm{O}\end{array}$ & 1 & 0.3819 & $\begin{array}{l}0.1728 \\
0.8458\end{array}$ & $\begin{array}{l}0.0874 \\
0.8250 \\
0.7424 \\
1\end{array}$ \\
\hline (b) & $\begin{array}{l}Y \\
M P \\
M C \\
O\end{array}$ & 1 & 0.2598 & $\begin{array}{l}0.2381 \\
0.9426\end{array}$ & $\begin{array}{l}0.0625 \\
0.8724 \\
0.8025 \\
1\end{array}$ \\
\hline
\end{tabular}

\section{DISCUSSION}

In Mytilus islands, some biological activities such as filtering, biodeposition and growth of $M$. edulis undoubtedly affect the process of community organization of associated animals. There may be biological reasons for a low recruitment by mussel larvae into the patch, e.g. predation by associated fauna or filtering by the patch-forming mussels. This may explain the low density of juvenile mussels in the patches MP, MC and $O$, because these patches were constructed by large mussels with high filtration rates (Winter 1973, 1978, Jørgensen 1975). Recruitment might be more successful in the younger patch $(Y)$.

Physical structure created by sessile organisms is an important characteristic of the system for associated fauna (Dean 1981). After larval settlement on the rock, a monolayer mussel bed is formed in the early stage of patch growth (Y). With growth, mussels require more space for attachment, and some individuals on the periphery of the patch are pushed out while some inside the patch are shifted up. This results in the formation of a double or multi-layered mussel bed (MC). With time, some mussels die, but some of the dead shells and fragments remain in the patches. The structure of Mytilus islands may change with growth and recruitment of the mussels. Hosomi (1967) reported a similar change in the physical structure of M. edulis populations with time on a breakwater in Osaka Bay, Japan. If further settlement of mussel larvae does not occur, only large mussels make up a monolayered bed (O). In such situations, the volume of patch per unit area becomes small and the height of a patch is less than that of double or multilayered younger patches.

The fact that the monolayered old patch (O) had a smaller amount of sediments and shell fragments than younger patches (MP and MC) and were poorer in species richness may suggest that more space and larger amounts of sediments and shell fragments in the patches may be needed for an increase in species diversity. Increase of sediments, shell fragments and byssal threads accelerate an increase of heterogeneity of habitat structure. In MP and MC, feeding habits of the associated animals were diverse including herbivores, deposit feeders, carnivores and suspension feeders. Organic matter in the sediments was richer in $\mathrm{MP}$, $\mathrm{MC}$ and $\mathrm{O}$ than in $\mathrm{Y}$. Deposit feeders use environments rich in organic matter, e.g. the cirratulid Cirriformia tentaculata, which is an indicator species of such an environment, was seen in these patches.

In the oldest patch (O), sessile animals such as barnacles and serpulids were found on Mytilus edulis shells. Growth of older mussels is slower than that of younger ones (Seed 1976). Because older part of shells do not grow, they are suitable substrates for sessile organisms.

On the other hand, there is a possibility that the sediment accumulation affects adversely the associated fauna, because super-abundant sediments prevent Mytilus edulis larvae from settling to patches (Field 1982) and generate a reducing environment (Tsuchiya 1979).

Species composition in $Y$ differed from those of other patches. Because $\mathrm{Y}$ is the youngest patch, it had provided the shortest period for invasion by associated animals. Since it is considered that those species found in $\mathrm{Y}$ settled also in older patches, interactions between inhabitants or early settlers and, new settlers might cause the death of the latter. Dynamic processes in a Mytilus island community, with reference to the immigration and recruitment of associated fauna, need to be studied in future. On the other hand, environmental traits may be unsuitable for animals inhabiting older patches because the patches may be affected by wave action or predators.

It has been reported that the Mytilus community is 


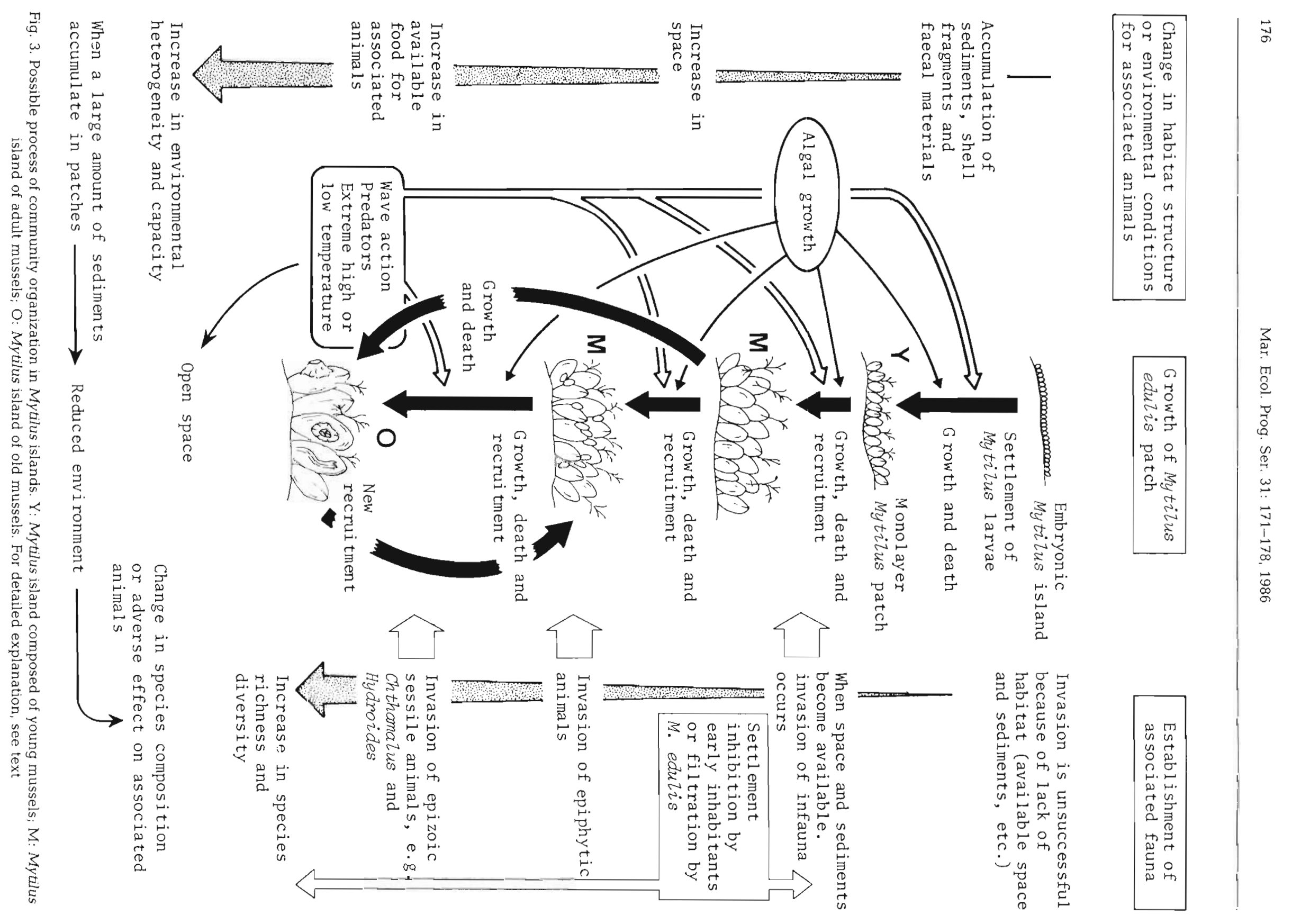


relatively stable (Sheer 1945, Dean \& Hurd 1980), because the mussel bed confers protection from external perturbations (Connell 1972). However, the periphery of patches is greatly affected by forces from outside, e.g. wave action and predators, etc. If so, it is conceivable that there are differences in faunal composition between peripheral and central parts in a patch. However, the species composition in MP and MC was very similar $\left(C_{\Pi}\right.$ based on all inhabitants being 0.8458). Environmental differentiation of the Mytilus island may occur only at a very peripheral part.

The role that algae growing in the patches play in community structure requires special attention. Many epiphytic amphipods were collected in $Y$, which was characterized by much algae (Table 1). Scarcity of amphipods in older patches could be explained by the poor algal growth.

Fig. 3 shows the possible process of community organization in Mytilus islands, which emerged from the results obtained in previous (Tsuchiya \& Nishihira 1985) and the present studies. The volume of each component of a Mytilus island varies from patch to patch. In $Y$, dead shells seem to be removed more easily by wave action than in the other older patches, because, presumably, the latters' insides are protected from wave action. Shell fragments may be accumulated in these patches, snared by byssal threads. $M$. edulis produces faeces and pseudofaeces which accumulate in the Mytilus bed (Seed 1976. Tsuchiya 1980). Because some resuspended bottom materials are present in shallow waters (Kiørboe et al. 1981), these may also be deposited in the patches. There is a possibility that detritus and micro-organisms on the shell surface are used as food for deposit feeders in the patch. Accumulations of sediments, shell fragments and faecal materials may play important roles in increasing species diversity through increasing environmental heterogeneity. Impacts from outside the Mytilus island may play an important role in community organization. Mytilus beds frequently receive adverse affects of some factors such as extreme temperatures or desiccation (Suchanek 1978. Tsuchiya 1983), wave action or drift logs (Dayton 1971, Paine \& Levin 1981) and predators (Paine 1974, Menge 1976). In such cases, open rock surface may appear on the intertidal and opportunistic species can invade it (Connell \& Slatyer 1977). In northern Japan, the barnacle Chthamalus challengeri is considered to be such an opportunistic species, because invasion of $C$. challengeri into the bared rock surface has frequently seen (Hoshiai 1960, 1965, Tsuchiya 1983).

In order to confirm these speculative processes of community organization, we must conduct many experimental analyses both in the field and laboratory.
Acknowledgements. Thanks are extended to the staff members of the Marine Biological Station, Tohoku University, and Laboratory of Animal Ecology, Tohoku University for their advice and to Professor R. T. Paine and Dr. T H. Suchanek for critical reading of the manuscript. This study was partially supported by a grant-in-aid from the Ministry of Education. Science and Culture, Japan (No. 57740346).

\section{LITERATURE CITED}

Connell, J. H. (1972). Community interaction on marine rocky intertidal shores. A. Rev. Ecol. Syst. 3: 169-192

Connell, J. H., Slatyer, R. O. (1977). Mechanisms of succession in natural communities and their role in community stability and organization. Am. Nat. 111: 1119-1144

Dayton, P. K. (1971). Competition, disturbance and community organization: The provision and subsequent utilization of space in a rocky intertidal community. Ecol. Monogr. 41: 351-389

Dean, T. A. (1981). Structural aspects of sessile invertebrates as organizing forces in an estuarine fouling community. J. exp. mar. Biol. Ecol. 53: 163-180

Dean, T. A., Hurd, L. E. (1980). Development in an estuarine fouling community: The influence of early colonies on later arrivals. Oecologia (Berl.) 46: 295-301

Field, B. (1982). Structural analysis of fouling community development in the Damariscotta River estuary, Maine. J. exp. mar. Biol. Ecol. 57: 25-33

Hewatt, W. G. (1935). Ecological succession in the Mytilus californianus habitat as observed in Monterey Bay, California. Ecology 16: 244-251

Hoshiai, T. (1960). Synecological study on intertidal communities III. An analysis of interrelation among sedentary organisms on artificially denuded rock surface. Bull. mar. Biol. Stn Asamushi, Tohoku Univ. 10: 49-56

Hoshiai, T. (1965). Synecological study on intertidal communities VI. A synecological study on the intertidal zonation on the Asamushi coast area with reference to its reformation. Bull. mar. Biol. Stn Asamushi, Tohoku Univ, 12: 93-126

Hosomi, A. (1967). Various types of physical structure of Mytilus edulis population in Suma coast. Hyogo Biol. 5: 237-241 (in Japanese)

Jørgensen, C. B. (1975). Comparative physiology of suspension feeding. A. Rev. Physiol. 37: 57-79

Kimoto, S. (1967). Some quantitative analysis on the Chrysomelid fauna of the Ryukyu Archipelago. Esakia 6: 27-54

Kiørboe, T., Møhlenberg, F., Nøhr, O. (1981). Effect of suspended bottom material on growth and energetics in Mytilus edulis. Mar. Biol. 61: 283-288

Menge, B. A. (1976). Organization of the New England rocky intertidal community: role of predation, competition and environmental heterogeneity. Ecol. Monogr. 46: 355-393

Paine, R. T. (1974). Intertidal community structure: Experimental studies on the relationship between a dominant competitor and its principal predator. Oecologia (Berl.) 15: 93-120

Paine, R. T., Levin, S. A. (1981). Intertidal landscapes: Disturbance and the dynamics of pattern. Ecol. Monogr. 51: $145-178$

Seed, R. (1976). Ecology. In: Bayne, B. L. (ed.) Marine mussels, their ecology and physiology. Cambridge University Press, Cambridge, p. 13-66

Sheer, B. T. (1945). The development of marine fouling communities. Biol. Bull. mar. biol. Lab., Woods Hole 89: 103-121 
Suchanek, T. H. (1978). The ecology of Mytilus edulis L. in exposed rocky intertidal communities. J. exp. mar Biol. Ecol. 31: 105-120

Suchanek, T. H. (1979). The Mytilus californianus community: studies on the composition, structure, organization and dynamics of a mussel bed. Ph.D. thesis, University of Washington, Seattle

Suchanek, T H. (1985). Mussels and their role in structuring rocky shore communities. In: Moore, P. G., Seed, R. (ed.) The ecology of rocky coasts. Hodder \& Stoughton, London, p. $70-96$

Tsuchiya, M. (1979). Quantitative survey of intertidal organisms on rocky shores in Mutsu Bay, with special reference to the influence of wave action. Bull. mar. Biol. Stn Asamushi, Tohoku Univ. 16: 69-86

Tsuchiya, M. (1980). Biodeposit production by the mussel
Mytilus edulis L. on rocky shores. J. exp. mar. Biol. Ecol. 47: 203-222

Tsuchiya, M. (1983). Mass mortality in a population of the mussel Mytilus edulis L. caused by high temperature on rocky shores. J. exp. mar. Biol. Ecol. 66: 101-111

Tsuchiya, M., Nishihira, M. (1985). Islands of Mytilus as a habitat for small intertidal animals: effect of island size on community structure. Mar. Ecol. Prog. Ser. 25: 71-81

Winter, J. E. (1973). The filtration rate of Mytilus edulis and its dependence on algal concentration, measured by a continuous automatic recording apparatus. Mar. Biol. 22: $317-328$

Winter, J. E. (1978). A review on the knowledge of suspension-feeding in lamellibranchiate bivalves, with special reference to artificial aquaculture systems. Aqquaculture 13: $1-33$

This article was submitted to the editor; it was accepted for printing on April 24, 1986 